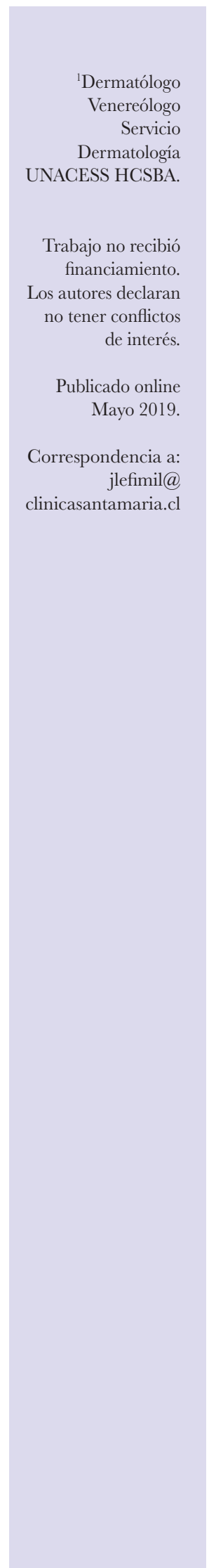

\title{
Editorial \\ Reafirmando nuestro rol como venereólogos
}

Juan Marcelo Lefimil ${ }^{1}$

$\mathrm{E}$

s preocupante y desbordante el aumento que tanto el VIH (Virus de la Inmunodeficiencia Humana) como las ITS (Infecciones de Transmisión Sexual) han sufrido en los últimos años.

Según informe de ONU SIDA ${ }^{1}$, desde el 2010 en nuestro país las infecciones de VIH nuevas se han incrementado en un 35\% y las muertes relacionadas con el SIDA en un $34 \%$. De las personas que viven con el VIH aproximadamente un $48 \%$ tiene carga viral intedectable; cifras que deben mejorar (actualmente se sabe que indetectable $=$ intransmisible ${ }^{2}$.

Por otro lado, tenemos las ITS, cuyo aumento repercute de manera negativa ya que, además de causar enfermedad aguda, son capaces de generar infertilidad, discapacidad a largo plazo (por ejemplo, neurosífilis) y tienen un rol facilitador de la transmisión del $\mathrm{VIH}^{3}$.

En Chile, en el año 2017, se documentó un aumento en la tasa de Gonorrea. Considerando los mecanismos de transmisión, es esperable que este aumento vaya de la mano con el aumento de otras ITS ${ }^{4}$.

Respecto a la Sífilis, si bien los resultados de vigilancia del MINSAL (Ministerio de Salud) han mostrado una estabilización de las tasas de notificación, esto puede ser debido a una subnotificación o falta de diagnóstico ${ }^{5-7}$. A nivel mundial existe preocupación por el aumento en las cifras de esta patología. En Estados Unidos, durante el período 20002017 se evidenció un incremento constante en tasas de Sífilis primaria y Secundaria en especial en HSH (hombres que tienen sexo con hombres). Otra gran preocupación es la gonorrea resistente a antibióticos que tam- bién se ha reportado con mayor prevalencia en este grupo ${ }^{3}$.

Los motivos del aumento de los casos de Sífilis aún no se conocen del todo, pero varios estudios han mostrado una disminución en el uso del condón tanto en HSH como HSM (hombres que tienen sexo con mujeres). En nuestro país la declaración de su uso es muy bajo $(10 \%)^{8}$.

Los factores que explican la alta incidencia de ITS en HSH incluyen comportamientos sexuales individuales como el número de parejas sexuales recientes y a lo largo de la vida, comportamientos seroadaptativos, entre otros. Los comportamientos seroadaptativos son conductas que buscan reducir el riesgo de transmisión del VIH como por ejemplo el serosorting (persona que elige pareja sexual con mismo status de VIH para tener sexo no protegido y así reducir riesgo de adquirir o transmitir el $\mathrm{VIH}$ ). Sin embargo, estas conductas resultan en un aumento del riesgo de contraer alguna ITS. Finalmente, cabe señalar que también existen factores sociales involucrados como experiencias de maltrato psicológico, discriminación y abuso físico que se asocian a comportamientos sexuales de riesgo ${ }^{2,9}$.

Además de existir problemas con el aumento en tasas de incidencia, por parte de los tratantes existe, por otro lado, tasas suboptimas de screening de ITS. Una experiencia en USA mostró que a menos de la mitad de las mujeres elegibles se les realizó pesquisa de Chlamydia. En países bajos se invitó a individuos de 16 a 29 años a someterse a pesquisa gratuita de esta infección y las tasas de participación fueron tan sólo de $16 \%{ }^{10}$. 
En PVVIH (personas viviendo con VIH) en control, el screening de Gonorrea y Chlamydia han mostrado cifras muy bajas (39\% en comparación a un $77 \%$ de screening de Sífilis). Otro estudio que involucró 4217 PVVIH mostró que en aquellos que se declaraban sexualmente activos los últimos 12 meses, sólo 55\% había sido testeado para Sífilis y 24\% para Gonorrea ${ }^{2,11}$.

El promover una vida sexual sana y segura debe considerar estrategias individuales y comunitarias bajo una mirada bio psicosocial y enfoque diferenciado hacia determinados grupos. Es por esto que en la estrategia nacional de salud para el período 2011-2020, se incorporó la prevención de ITS como objetivo prioritario ${ }^{12}$.

Como Dermatólogos y Venereólogos, no debemos olvidar los orígenes de nuestra especialidad, tan ligados al diagnóstico y tratamiento de las ITS. Somos un pilar fundamental en el reconocimiento precoz de estas entidades, y no debemos abandonarlas en nuestra práctica clínica diaria tanto pública como privada.

Nuestro rol no es sólo tratar. Debemos ser capaces de cambiar la percepción de riesgo que tiene el paciente respecto a su vida sexual y empoderarlo de estrategias preventivas adecuadas para evitar adquisición y transmisión de ITS y VIH. Del mismo modo, debemos acoger con empatía y una visión integral a grupos que tienen necesidades de salud específicas como HSH, bisexuales, lesbianas y población trans.
BIBLIOGRAFÍA

1. ONUSIDA. País: Chile. Disponible en http://www.unaids.org/es/ regionscountries/countries/chile

2. Centers for disease control and prevention. HIV Treatment as prevention. Disponible en https://www.cdc.gov/hiv/risk/art/index.html

3. Centers for disease control and prevention. Sexually Transmitted Disease Surveillance 2017. Disponible en https://www.cdc.gov/std/stats17/ default.htm

4. Chile, Ministerio de Salud. Informe vigilancia gonorrea 2017. http://epi. minsal.cl/wp-content/uploads/2017/07/BET_GONORREA_JULIO. pdf

5. Chile, Ministerio de Salud . Informe situación epidemiológica ITS 2016. Disponible en http://epi.minsal.cl/wp-content/uploads/2017/10/ Situacion_ITS_2016.pdf

6. Chile, Ministerio de Salud, Informe situación epidemiológica de sífilis chile 2016. Disponible en http://epi.minsal.cl/wp-content/ uploads/2018/02/Inf-anual-S\%C3\%ADfilis-2016finalpublicado.pdf

7. Chile, Ministerio de Salud. Informe de vigilancia de sífilis 2017. Disponible en http://epi.minsal.cl/wp-content/uploads/2017/08/ BET_SIFILIS_JULIO.pdf

8. Chile, Ministerio de Salud. Encuesta Nacional de Salud 2016-2017. Disponible en https://www.minsal.cl/wp-content/uploads/2017/11/ ENS-2016-17_PRIMEROS-RESULTADOS.pdf

9. Khosropour CM., Dombrowski JC., Swanson F., et al. Trends in Serosorting and the Association With HIV/STI Risk Over Time Among Men Who Have Sex With Men . J Acquir Immune Defic Syndr. 2016 Jun 1;72(2):189-97

10. Van den Broek IV, Van Bergen Je, et al. Effectiveness of yearly, register based screening for chlamydia in the Netherlands: controlled trial with randomised stepped wedge implementation. BMJ 2012; 345:e4316

11. Paz-Bailey G, Hall H I, Wolitski R J,Prejean J, Handel M M Van, Le B, et al.HIV testing and risk behaviors among gay,bisexual, and other men who have sex with men - United States. MMWR Morb Mortal Wkly Rep [Internet]. 2013; 62 (47): 945-52. Disponible en: http://www.ncbi.nlm. nih.gov/pubmed/24280913

12. Chile,MinisteriodeSalud.Estrategianacionaldesalud2011-2020.https:// www.minsal.cl/portal/url/item/c4034eddbc96ca6de0400101640159b8. pdf 